\title{
Diagnosis and management of the overlap syndromes of autoimmune hepatitis
}

\author{
Albert J Czaja MD
}

AJ Czaja. Diagnosis and management of the overlap syndromes of autoimmune hepatitis. Can J Gastroenterol 2013;27(7): 417-423.

BACKGROUND: Autoimmune hepatitis may have cholestatic features that are outside the classical phenotype and that resemble findings in other immune-mediated liver diseases. These cholestatic phenotypes have been designated 'overlap syndromes'.

OBJECTIVES: To recognize the overlap syndromes in adults and manage them appropriately.

METHODS: The MEDLINE database was reviewed for published experiences from 1984 to 2013.

RESULTS: Patients with autoimmune hepatitis may exhibit features of primary biliary cirrhosis ( $7 \%$ to $13 \%$ ), primary sclerosing cholangitis ( $6 \%$ to $11 \%$ ) or a cholestatic syndrome without other diagnostic features (5\% to $11 \%)$. These mixed phenotypes may represent classical autoimmune hepatitis with atypical features, transition states in the evolution of classical cholestatic syndromes, concurrent separate diseases or pathogenically distinct disorders. The 'Paris criteria' have been endorsed for the diagnosis of the overlap syndrome with primary biliary cirrhosis, and treatment with conventional immunosuppressive therapy alone or in combination with low-dose ursodeoxycholic acid can be guided by the serum alkaline phosphatase level. The overlap syndrome with primary sclerosing cholangitis or with cholestasis without diagnostic features is commonly treated with immunosuppressive therapy and ursodeoxycholic acid. Responses are variable and commonly incomplete ( $20 \%$ to $100 \%$ improvement) depending on the degree of cholestasis.

DISCUSSION: The overlap syndromes are clinical descriptions rather than pathological entities, and the dominant component of the disease determines its designation and therapy. Cholestatic findings in autoimmune hepatitis influence the response to immunosuppressive therapy.

CONCLUSION: The overlap syndromes must be considered in patients with autoimmune hepatitis and cholestatic findings, concurrent inflammatory bowel disease or steroid-refractory disease.

Key Words: Autoimmune; Cholestasis; Hepatitis; Management; Overlap; Variants

The overlap syndromes of autoimmune hepatitis (AIH) are hybrid conditions that cannot be assimilated into classical diagnostic categories (1-6). Patients with AIH may exhibit features of primary biliary cirrhosis (PBC), primary sclerosing cholangitis (PSC), or a cholestatic syndrome in the absence of objective features of $\mathrm{PBC}$ or PSC (6). The common clinical feature of these atypical phenotypes is the presence of a cholestatic component $(7,8)$, and the major clinical relevance of these syndromes is their failure to respond in a consistent fashion to conventional corticosteroid therapy $(2,6,8)$. The overlap syndromes are clinical descriptions rather than distinct pathological entities. They are important in clinical practice because they are relatively common, have uncertain clinical outcomes and require nonstandard treatments $(2,6,9)$.

\section{Le diagnostic et la prise en charge des syndromes de chevauchement de l'hépatite auto-immune}

HISTORIQUE : L'hépatite auto-immune peut avoir des caractéristiques cholestatiques qui ne font pas partie du phénotype classique et qui ressemblent aux manifestations d'autres maladies hépatiques à médiation immune. Ces phénotypes cholestatiques sont désignés par le terme «syndromes de chevauchement ».

OBJECTIFS : Diagnostiquer les syndromes de chevauchement chez les adultes et les traiter correctement.

MÉTHODOLOGIE : Les chercheurs ont analysé la base de données MEDLINE pour obtenir les expériences publiées entre 1984 et 2013.

RÉSULTATS : Les patients ayant une hépatite auto-immune peuvent présenter des caractéristiques de cirrhose biliaire primitive (7 \% à $13 \%$ ), de cholangite sclérosante primitive (6\% à $11 \%)$ ou de syndrome cholestatique sans autres caractéristiques diagnostiquées (5 \% à $11 \%$ ). Ces phénotypes mixtes peuvent être indicateurs d'une hépatite autoimmune classique aux caractéristiques atypiques, d'états de transition dans l'évolution de syndromes cholestatiques classiques, de maladies distinctes concomitantes ou de troubles distincts sur le plan pathogène. Les « critères de Paris » sont acceptés pour diagnostiquer un syndrome de chevauchement lié à une cirrhose biliaire primitive, et le traitement à l'aide de l'immunothérapie seule ou en association avec une faible dose d'acide ursodésoxycholique peut être orienté par le taux de phosphatase alcaline sérique. Le syndrome de chevauchement lié à une cholangite sclérosante primitive ou à une cholestase sans caractéristiques diagnostiques est souvent traité par des immunosuppresseurs et de l'acide ursodésoxycholique. Les réponses sont variables et souvent incomplètes (amélioration de $20 \%$ à $100 \%$ ), selon la gravité de la cholestase.

EXPOSÉ : Les syndromes de chevauchement sont des descriptions cliniques plutôt que des entités pathologiques, et l'élément dominant de la maladie en détermine la désignation et le traitement. Les observations cholestatiques de l'hépatite auto-immune influent sur la réponse à la thérapie immunosuppressive.

CONCLUSION : Il faut envisager des syndromes de chevauchement chez les patients ayant une hépatite auto-immune et des manifestations cholestatiques, une maladie inflammatoire de l'intestin concomitante ou une maladie réfractaire aux stéroïdes.

Alkaline phosphatase levels exceed the upper limit of the normal range (ULN) by twofold in only $21 \%$ of patients with classical $\mathrm{AIH}$ and never exceed fourfold ULN (8). Histological features of bile duct injury primarily reflect nondestructive lymphocytic or pleomorphic cholangitis (10), and concurrent features of destructive cholangitis ('florid duct lesions') are typically rare, isolated and transient (11-13). The presence of pruritus or hyperpigmentation challenges the likelihood of AIH (14), and the codified international diagnostic criteria for AIH (7) and the original diagnostic scoring system of the International Autoimmune Hepatitis Group (IAIHG) (15) exclude cholestatic components from the phenotype $(7,16,17)$.

The exclusion of cholestatic features from the classical definition of AIH does not exclude them from clinical experience, and multiple

Division of Gastroenterology and Hepatology, Mayo Clinic College of Medicine, Rochester, Minnesota, USA

Correspondence: Dr Albert J Czaja, Mayo Clinic College of Medicine, 200 First Street Southwest, Rochester, Minnesota 55905, USA.

Telephone 507-284-8118, fax 507-284-0538, e-mail czaja.albert@mayo.edu

Received for publication March 14, 2013. Accepted May 6, 2013 
TABLE 1

Diagnostic features of the overlap syndromes of autoimmune hepatitis (AIH)

\begin{tabular}{|c|c|c|c|c|}
\hline Overlap syndrome & Laboratory features & $\begin{array}{l}\text { Serological } \\
\text { features }\end{array}$ & Histological features & $\begin{array}{l}\text { Cholangiographic } \\
\text { findings }\end{array}$ \\
\hline \multirow[t]{2}{*}{ AlH-PBC } & Consistent with Paris criteria* $(19,30)$ & AMA positive (2) & Interface hepatitis (30) & Normal (6) \\
\hline & Mild forms may have AP $\leq 2 \times \operatorname{ULN}(2,6)$ & & Destructive cholangitis (florid duct lesions) (30) & \\
\hline \multirow{3}{*}{ AlH-PSC } & Y-globulin and $\lg G>U L N(2)$ & & Ductopenia (34) & $(2,18,20,72)$ \\
\hline & AP or GGT>ULN (2) & & Portal edema or fibrous (34) & \\
\hline & & & Obliterative fibrous cholangitis (rare) (34) & \\
\hline \multirow{2}{*}{$\begin{array}{l}\text { AlH-cholestatic } \\
\text { syndrome }\end{array}$} & Y-globulin and IgG >ULN (2) & & Destructive cholangitis or bile duct loss $(11,27)$ & \\
\hline & AP or GGT > ULN (2) & & & \\
\hline
\end{tabular}

Numbers in parentheses refer to references. *Paris criteria endorsed by the European Association for the Study of the Liver require interface hepatitis and either serum alanine aminotransferase (ALT) level $\geq 5$-fold upper limit of normal range (ULN), serum immunoglobulin $G$ (IgG) level $\geq 2$-fold ULN or smooth muscle antibodies, and two of three features of primary biliary cirrhosis (PBC) including serum alkaline phosphatase (AP) level $\geq 2$-fold ULN or serum gamma glutamyl transferase (GGT) $\geq 5$-fold ULN, antimitochondrial antibodies (AMA) and destructive cholangitis. AST Serum aspartate aminotransferase level; PSC Primary sclerosing cholangitis

reports attest to their occurrence in otherwise classical disease $(5,6,9,18-24)$. This realization has indicated the need to recognize these variant syndromes and manage them effectively. The goal of the present review was to meet this need.

\section{TYPES OF OVERLAP SYNDROMES OF AIH}

The overlap syndromes of AIH imply that the predominant disease is $\mathrm{AIH}$ and that the concurrent cholestatic features are background components $(5,6)$. In this context, AIH has three cholestatic phenotypes that may be intermixed with its classical hepatitic features (Table 1). Patients may have antimitochondrial antibodies (AMA) and histological findings of bile duct injury or loss that suggest PBC (AIH-PBC overlap) (5,6). They may have absence of AMA and endoscopic retrograde (ERC) and magnetic resonance (MRC) cholangiograms that suggest PSC (AIH-PSC overlap) $(5,6)$. They may also have a cholestatic syndrome characterized by the absence of AMA, normal ERC or MRC, and histological features of bile duct injury or loss (AIH-cholestatic syndrome) (6,11). The AIH-cholestatic syndrome may include patients with AMA-negative PBC or small-duct PSC $(6,11,25-27)$.

Patients with the AIH-PBC overlap syndrome are different from patients with predominately $\mathrm{PBC}$ and incidental features of $\mathrm{AIH}$ (PBC-AIH overlap syndrome) (6). Similarly, patients with the AIHPSC overlap syndrome are different from patients with predominantly PSC and incidental features of AIH (PSC-AIH overlap syndrome) (6). The predominant disease in the overlap syndrome determines its principal clinical manifestations and outcome $(5,6)$. In contrast to patients with the AIH-PBC overlap syndrome, patients with the PBCAIH overlap syndrome frequently have cirrhosis, portal hypertension, gastrointestinal bleeding, ascites and esophageal varices $(28,29)$. Similarly, patients with the PSC-AIH overlap syndrome (20) may respond less well to conventional corticosteroid therapy than patients with the AIH-PSC overlap syndrome (18). The overlap syndromes of $\mathrm{AIH}$ are important to distinguish from the overlap syndromes of $\mathrm{PBC}$ and PSC, and the various mixtures of $\mathrm{AIH}, \mathrm{PBC}$ and PSC must be categorized according to their major component and not consolidated into categories that give equal weight to each constituent $(2,4-6)$.

\section{DIAGNOSTIC CRITERIA FOR THE OVERLAP SYNDROMES OF AIH}

The diagnosis of the overlap syndromes of AIH has not been codified; however, the importance of having prominent features of classical $\mathrm{AIH}$ and secondary objective findings of PBC or PSC has been emphasized by the IAIHG (5), the European Association for the Study of the Liver (EASL) (30) and the American Association for the Study of Liver Diseases (31). The AIH component must be established by demonstrating satisfaction of the codified diagnostic criteria for this disease based on clinical features or scoring systems (either the original comprehensive or simplified systems) $(7,32)$. The definite or probable diagnosis of $\mathrm{AIH}$ according to these criteria is a requisite for the syndrome (33), and the predominant histological features should be interface hepatitis with or without plasma cells (34).

\section{Diagnostic criteria for the AIH-PBC overlap syndrome}

The minimum diagnostic criteria for the AIH-PBC overlap syndrome are the presence of AMA and histological findings of bile duct injury or loss in otherwise classical AIH (Table 1) $(2,6)$. The serum alkaline phosphatase level and the histological findings of destructive cholangitis indicate the strength of the association with $\mathrm{PBC}$, and they direct the management strategy $(19,35)$. Other histological findings may include portal or acinar granulomas, cholate stasis and nondestructive lymphocytic cholangitis $(34,36)$. The 'Paris criteria' provide an objective basis for making the diagnosis of the overlap syndrome with $\mathrm{PBC}$ and they ensure uniformity of the diagnosis (Table 1) $(19,30,35)$. They encompass patients with the strongest manifestations of the AIH-PBC overlap syndrome.

The Paris criteria for the AIH-PBC overlap syndrome require two of three features associated with $\mathrm{AIH}$ selected from the following: serum alanine aminotransferase level $\geq 5$-fold ULN, immunoglobulin $G$ level $\geq 2$-fold ULN or the presence of smooth muscle antibodies, and interface hepatitis on histological examination (19). They also require two of three features associated with $\mathrm{PBC}$ selected from the following: serum alkaline phosphatase level $\geq 2$-fold ULN or $\gamma$-glutamyl transferase (GGT) level $\geq 5$-fold ULN, AMA, and florid duct lesions or destructive cholangitis on histological examination (19). The Paris criteria have a sensitivity of $92 \%$ and specificity of $97 \%$ using clinical judgment as the gold standard (37), and they have been endorsed by the EASL with the stipulation that all patients with this syndrome have interface hepatitis $(5,30)$.

\section{Diagnostic criteria for the AIH-PSC overlap syndrome}

Cholangiographic changes indicating focal strictures and dilations of the biliary tree are characteristic of PSC by ERC or MRC, and patients with classical $\mathrm{AIH}$ and these radiological findings warrant the diagnosis of the AIH-PSC overlap syndrome (Table 1) $(2,5,6)$. Histological changes may disclose interface hepatitis with or without plasma cells, portal edema or fibrosis, ductopenia, ductal tortuosity, ductular proliferation, cholate stasis or, rarely, obliterative fibrous cholangitis $(34,36)$. Concurrent inflammatory bowel disease is common in adults with this overlap syndrome (38), but its absence does not preclude the diagnosis (39). Routine cholangiography has not been promulgated for adults with classical $\mathrm{AIH}$ in the absence of inflammatory bowel disease (40), and the detection of the AIH-PSC overlap syndrome in adults is typically driven by the presence of chronic ulcerative colitis, marked cholestatic features or poor treatment response $(2,6,38)$. Children with AIH frequently have 'autoimmune sclerosing cholangitis' in the 
absence of inflammatory bowel disease; the threshold for cholangiography may be lower in this population $(41,42)$.

\section{Diagnostic criteria for the AIH-cholestatic overlap syndrome}

The diagnosis of the AIH-cholestatic overlap syndrome implies the absence of serological and histological features diagnostic of PBC and the presence of a normal cholangiogram (Table 1). The designation may encompass patients with AMA-negative PBC or small duct PSC $(27,43)$, and the heterogeneity of this category is suggested by the diversity of histological manifestations. Patients with this syndrome may have a dense lymphoplasmacytic portal infiltrate with interface hepatitis and bile duct injury suggestive of PBC, or portal fibrosis, portal edema and ductopenia reminiscent of PSC (34). The AIHcholestatic overlap syndrome probably existed earlier under the rubric of 'autoimmune cholangitis' (11,43-48).

\section{FREQUENCIES OF THE OVERLAP SYNDROMES OF AIH}

The frequencies of the overlap syndromes in patients with AIH vary widely depending on the diagnostic criteria that are applied. In a compilation of reported experiences (6), $7 \%$ to $13 \%$ of patients with $\mathrm{AIH}$ have overlapping features of $\mathrm{PBC} ; 6 \%$ to $11 \%$ of patients have features of PSC; and $5 \%$ to $11 \%$ have a cholestatic syndrome in the absence of $\mathrm{PBC}$ and large duct PSC. The estimated overall frequency of an overlap syndrome in a well-defined cohort of patients with classical AIH is $14 \%$ to $18 \%(2,9)$. The presence of inflammatory bowel disease in patients with AIH favours the existence of the AIH-PSC syndrome, and $41 \%$ of adults with AIH and chronic ulcerative colitis have cholangiographic features of PSC (38). This finding has justified a recommendation that cholangiography be considered in all adults with $\mathrm{AIH}$ and inflammatory bowel disease $(6,38)$.

Endoscopic cholangiography in children with AIH has disclosed biliary changes of 'autoimmune sclerosing cholangitis' in 50\% (41), and MRC in adults with AIH has disclosed biliary changes of PSC in $10 \%$ (39). Most children and adults with AIH who have cholangiographic abnormalities were female, and they had no clinical evidence of inflammatory bowel disease. These observations suggested that patients with otherwise classical AIH could have an unsuspected biliary disease in the absence of inflammatory bowel disease and that this occurrence was underestimated.

Importantly, these observations did not include a disease-control population to establish the disease specificity of the radiological findings. A subsequent French study performed MRC in adults with AIH and adults with nonautoimmune chronic liver disease, and it found that the frequency of bile duct changes was similar between the patient groups (44\% versus 59\%) and that PSC was rare in $\mathrm{AIH}(2 \%)$ (40). The hepatic fibrosis score was the only independent predictor of the biliary changes by MRC (OR 2.4 [95\% CI 1.4 to 1.7 ), and advanced hepatic fibrosis rather than an unsuspected PSC was most closely associated with the MRC changes (40). These findings do not justify the routine performance of cholangiography in adults with classical $\mathrm{AIH}$ and no inflammatory bowel disease.

\section{PATHOGENIC HYPOTHESES FOR THE OVERLAP SYNDROMES OF AIH}

The overlap syndromes of $\mathrm{AIH}$ are clinical descriptions rather than valid pathological entities, and their true nature is uncertain $(6,49)$. The overlap syndromes may simply represent a classical disease with variant or atypical manifestations (50). They could represent a transition stage in the evolution of classical PBC or PSC in which mixed features are present during an early formative period $(34,36)$. They could represent two diseases in the same individual, or they could be separate pathological entities with their own yet undiscovered and distinctive pathogenic mechanisms (49).

\section{Overlap syndromes as variants of classical AIH}

The autoimmune liver diseases undoubtedly have blurred outer boundaries of diagnosis that cannot be rigidly defined, and the distinction
TABLE 2

Pathogenic hypotheses for the overlap syndromes of autoimmune hepatitis (AIH)

\begin{tabular}{|c|c|c|}
\hline Hypothesis & Theoretical bases & Clinical evidence \\
\hline $\begin{array}{l}\text { Classical AlH } \\
\text { with atypical } \\
\text { features }\end{array}$ & $\begin{array}{l}\text { AlH features not disease } \\
\text { specific (52) } \\
\text { AlH features occur in multiple } \\
\text { acute and chronic liver } \\
\text { diseases (16) } \\
\text { Diagnostic scoring systems } \\
\text { are based on classical AlH } \\
\text { and not valid in atypical } \\
\text { phenotypes }(7,32)\end{array}$ & $\begin{array}{l}\text { AIH overlapping with PBC or } \\
\text { PSC can respond to } \\
\text { conventional corticosteroid } \\
\text { therapy }(2,18,20,41) \\
\text { AIH, PBC and PSC have } \\
\text { many shared laboratory, } \\
\text { serological, genetic and } \\
\text { histological findings that are } \\
\text { not disease specific }(59)\end{array}$ \\
\hline $\begin{array}{l}\text { Transitional } \\
\text { stage in } \\
\text { evolution to } \\
\text { classical } \\
\text { PBC or PSC }\end{array}$ & $\begin{array}{l}\text { Autoimmune liver diseases } \\
\text { evolve through early } \\
\text { formative stages that have } \\
\text { mixed features }(34,59)\end{array}$ & $\begin{array}{l}\text { Histological findings are } \\
\text { indistinguishable among } \\
\text { PBC, stage } 2 \text { and AIH (34) } \\
\text { AlH has evolved into PBC } \\
\text { and PSC, and PBC has } \\
\text { evolved into AlH (53-55) }\end{array}$ \\
\hline $\begin{array}{c}\text { Concurrent } \\
\text { separate } \\
\text { diseases }\end{array}$ & $\begin{array}{l}\text { Common genetic factors in } \\
\text { AIH, PBC and PSC may } \\
\text { predispose to concurrent } \\
\text { separate diseases (59) }\end{array}$ & $\begin{array}{l}\text { Highly disease-specific } \\
\text { findings (cholangiographic } \\
\text { changes, destructive } \\
\text { cholangitis) occur in AlH } \\
\text { (49) } \\
\text { PBC and PSC have } \\
\text { coexisted (60-62) }\end{array}$ \\
\hline $\begin{array}{r}\text { Unrecognized } \\
\text { new disease }\end{array}$ & $\begin{array}{l}\text { Promiscuous immune } \\
\text { response can target multiple } \\
\text { targets in liver and biliary } \\
\text { tree and create various } \\
\text { phenotypes }(63,75)\end{array}$ & None \\
\hline
\end{tabular}

Numbers in parentheses refer to references. PBC Primary biliary cirrhosis; PSC Primary sclerosing cholangitis

between a hepatitic PBC and cholestatic AIH may be difficult $(21,50)$. The overlap syndromes of AIH may be at the fringe of the diagnosis of $\mathrm{AIH}$, but still be within the domain of that disease (Table 2). The original goal of the IAIHG was to develop diagnostic criteria that identified a homogeneous population that could be assimilated into clinical studies $(7,15)$. The failure of some forms of AIH to satisfy the current diagnostic criteria for AIH does not exclude them from the diagnosis. The overlap syndromes of AIH may, in part, be consequences of diagnostic criteria that are inadequate, misapplied or invalid $(6,51,52)$. Furthermore, the diagnostic scoring systems of the IAIHG are not discriminative diagnostic indexes, and the declaration that patients with PBC or PSC have AIH based on these scoring systems is presumptuous.

\section{Overlap syndromes as transitional stages}

The autoimmune liver diseases can evolve through different stages, and they may have mixed features at early stages of development (Table 2). Observations during these transitional stages may confound the diagnosis and suggest an overlap syndrome that actually represents an immature classical disease (6). Spontaneous transitions from $\mathrm{AIH}$ to PBC (53), AIH to PSC $(54)$ and PBC to AIH $(55,56)$ may be examples of this evolutionary pathway. Furthermore, serological markers, especially antinuclear and smooth muscle antibodies, are common findings in PBC, PSC and AIH that can suggest concurrent diseases (57), and AMA in $13 \%$ of patients with classical AIH can mistakenly suggest an association with PBC (58). Hypergammaglobulinemia and the human leukocyte antigen (HLA) DRB1*03 occur frequently in white North American and northern European patients with AIH, PBC or PSC (59), and the histological features of AIH may be difficult to distinguish from stage $2 \mathrm{PBC}$ or the early portal inflammatory changes of PSC (34). The clinical, serological and histological features that 
TABLE 3

Empirical treatments and outcomes of the overlap syndromes of autoimmune hepatitis (AlH)

\begin{tabular}{|c|c|c|}
\hline Overlap syndrome & Treatment & Outcomes \\
\hline AlH-PBC (AP $\leq 2$-fold ULN) & $\begin{array}{l}\text { Prednisone or prednisolone (52): } \\
30 \mathrm{mg} \text { daily } \times 1 \text { week } \\
20 \mathrm{mg} \text { daily } \times 1 \text { week } \\
15 \mathrm{mg} \text { daily } \times 2 \text { weeks } \\
10 \mathrm{mg} \text { daily thereafter } \\
\text { Combined with azathioprine }(52) \text { : } \\
50 \mathrm{mg} \text { daily from start, or } \\
1 \mathrm{mg} / \mathrm{kg} / \text { day to } 2 \mathrm{mg} / \mathrm{kg} / \text { day (European preference) }\end{array}$ & $\begin{array}{l}\text { Normal or near-normal tests and liver tissue } 81 \% \\
\text { (2) } \\
\text { Treatment failure } 14 \%(2)\end{array}$ \\
\hline AlH-PBC (Paris criteria*) & $\begin{array}{l}\text { Prednisone or prednisolone in combination with azathioprine as above } \\
\text { combined with UDCA: } 13 \mathrm{mg} / \mathrm{kg} / \text { day to } 15 \mathrm{mg} / \mathrm{kg} / \mathrm{day}(19,30)\end{array}$ & $\begin{array}{l}\text { Serum AP, GGT and ALT levels improve }(19,35) \\
\text { Limits hepatic fibrosis }(35)\end{array}$ \\
\hline AlH-PSC (adults) & $\begin{array}{l}\text { Prednisone or prednisolone } 0.5 \mathrm{mg} / \mathrm{kg} / \text { day tapered to } 10 \mathrm{mg} / \text { day to } 15 \mathrm{mg} / \mathrm{day} \\
\text { Combined with azathioprine } 50 \mathrm{mg} / \mathrm{day} \text { to } 75 \mathrm{mg} / \mathrm{day} \\
\text { Combined with UDCA } 13 \mathrm{mg} / \mathrm{kg} / \mathrm{day} \text { to } 15 \mathrm{mg} / \mathrm{kg} / \mathrm{day}(5,30,31,72)\end{array}$ & $\begin{array}{l}\text { Laboratory improvement variable in adults } \\
\qquad(2,18,27,38,72) \\
\text { Uncertain survival advantage in adults (20) }\end{array}$ \\
\hline AlH-cholestatic syndrome & $\begin{array}{l}\text { Prednisone or prednisolone in combination with azathioprine as above } \\
\text { combined with UDCA: } 13 \mathrm{mg} / \mathrm{kg} / \mathrm{day} \text { to } 15 \mathrm{mg} / \mathrm{kg} / \mathrm{day}(2,11,27)\end{array}$ & $\begin{array}{l}\text { Uncertain response }(2,11,27) \\
\text { Disease progression } 17 \%(2) \\
\text { Transplantation } 33 \%(2)\end{array}$ \\
\hline
\end{tabular}

Numbers in parentheses refer to references. ${ }^{*}$ Paris criteria include interface hepatitis and either serum alanine aminotransferase (ALT) level $\geq 5$-fold upper limit of normal range (ULN), immunoglobulin G level $\geq 2$-fold ULN or smooth muscle antibodies and two of the following, serum alkaline phosphatase (AP) level $\geq 2$-fold ULN or serum gamma glutamyl transferase (GGT) level $\geq 5$-fold ULN, antimitochondrial antibodies and destructive cholangitis. PBC Primary biliary cirrhosis; PSC Primary sclerosing cholangitis; UDCA Ursodeoxycholic acid

are shared by AIH, PBC, and PSC may partly explain the difficulty in separating these entities into separate categories and the tendency to assume overlapping diseases in patients with mixed features.

Overlap syndromes as concurrent diseases

The overlap syndromes of AIH may represent two diseases (AIH and PBC or PSC) occurring simultaneously in the same individual (49) (Table 2). This hypothesis is justified by the presence of highly diseasespecific findings of $\mathrm{PBC}$ or PSC in some patients with otherwise classical AIH $(6,49)$ and the concurrence of PBC and PSC (60-62). Furthermore, AIH, PBC and PSC share genetic factors that may predispose susceptible individuals to develop concurrent separate diseases $(59,63)$. Cholangiographic changes that include focal biliary strictures and dilations (31) and histological findings of destructive cholangitis or obliterative fibrous cholangitis $(10,64)$ are so disease-specific for $\mathrm{PBC}$ and PSC that their presence in patients with AIH supports the possibility of coexistent diseases. It also challenges the validity and the primacy of the diagnosis of concurrent $\mathrm{AIH}$ in patients with these predominant features. Because the diagnostic manifestations of $\mathrm{AIH}$ lack disease specificity, their occurrence in patients with unequivocal features of PSC or PBC may reflect variants of PSC or PBC rather than a concurrent AIH. Validation of the two-disease hypothesis in $\mathrm{AIH}$ requires the identification of a disease-specific feature of $\mathrm{AIH}$ that can be assessed in patients with definite PBC or PSC.

\section{Overlap syndromes as distinct diseases}

The overlap syndromes of AIH could represent distinct pathological entities with disease-specific pathogenic mechanisms, genetic predispositions, outcomes and treatment requirements (6). Self-antigens or foreign antigens that mimic self-antigens could initiate promiscuous immune responses that overcome self-tolerance and target hepatocytes, intrahepatic bile ducts and the extrahepatic biliary tree in genetically susceptible individuals $(63,65)$. Different patterns of injury within the liver and contiguous structures could reflect this unfocused and poorly regulated immune response and create a phenotype with mixed features. Rather than two diseases occurring simultaneously in one person, the mixed phenotype could reflect a single complex disease with distinctive yet undiscovered immune regulatory defects and genetic predispositions $(6,63)$. There have been no studies to advance or discount this conjecture.

\section{TREATMENT AND OUTCOMES OF THE OVERLAP SYNDROMES OF AIH}

The overlap syndromes of AIH have a variable response to conventional corticosteroid therapy (2) and they have a higher probability of recurrence after liver transplantation than patients with classical AIH (five-year probability of recurrence: $53 \%$ versus $17 \%$ ) (66). This variability of response and behaviour may, in part, relate to the degree of variance of the overlap syndrome from classical AIH (6). Serum alkaline phosphatase level and the histological findings of bile duct injury or loss are the principal indicators of this variance, and the strength of the cholestatic component, as reflected in these indexes, directs the management strategy $(4,8,19)$. Treatments are empirical and highly individualized, but they typically include corticosteroids alone or in combination with low-dose ursodeoxycholic acid ( $13 \mathrm{mg} / \mathrm{kg}$ to $15 \mathrm{mg} / \mathrm{kg}$ daily) $(2,4-6,9)$.

Treatment and outcome of the AIH-PBC overlap syndrome Patients with features of $\mathrm{AIH}$ and $\mathrm{PBC}$ who have a serum alkaline phosphatase level less than two-fold ULN respond as well to corticosteroid therapy as patients with classical autoimmune hepatitis (2) (Table 3). They achieve normal or near-normal liver tests and liver tissue as commonly ( $81 \%$ versus $86 \%$ ), and they fail treatment (worsen during therapy) as infrequently (14\% versus 9\%) (2). These patients have a strong resemblance to classical $\mathrm{AIH}$, and they can be treated as $\operatorname{such}(2,4)$.

In contrast, patients with the AIH-PBC overlap syndrome who satisfy Paris criteria by having serum alkaline phosphatase levels $\geq 2$-fold ULN are commonly treated with corticosteroids in combination with low-dose ursodeoxycholic acid ( $13 \mathrm{mg} / \mathrm{kg}$ to $15 \mathrm{mg} / \mathrm{kg}$ daily) (Table 3). This combination significantly improves the serum alkaline phosphatase $(\mathrm{P}<0.05)$, GGT $(\mathrm{P}<0.02)$ and alanine aminotransferase $(\mathrm{P}<0.02)$ levels $(19)$, prevents progressive hepatic fibrosis $(\mathrm{P}<0.04)$ $(19,35)$, and induces clinical and laboratory improvement more frequently than treatment with corticosteroids or ursodeoxycholic acid alone (9). In some patients, the resemblance to PBC may be so strong that treatment with ursodeoxycholic acid alone $(13 \mathrm{mg} / \mathrm{kg}$ to $15 \mathrm{mg} / \mathrm{kg}$ daily) is sufficient (67). Combined therapy has been endorsed by the EASL for patients satisfying the Paris criteria with the recognition that this recommendation is not strongly evidence based $(5,30)$. 
Treatment and outcome of the AIH-PSC overlap syndrome

Adults with the AIH-PSC overlap syndrome may respond to conventional corticosteroid therapy $(18,20,27)$ (Table 3$)$; however, they typically achieve normal or near-normal liver tests and liver tissue less frequently (20\% versus $86 \%$ ) $(2,38)$, fail treatment more often $(80 \%$ versus $14 \%)(2,38)$ and have a poorer survival than adults with classical AIH (20). In contrast, children with $\mathrm{AIH}$ and 'autoimmune sclerosing cholangitis' commonly respond to conventional corticosteroid therapy (frequency of improvement 89\%) (41,42), and immunosuppressive therapy remains the preferred treatment for these children (68) (Table 3). Unfortunately, corticosteroid treatment does not prevent progression of the cholangiopathy in some children (41) and the transplant-free survival in these children is shorter than that in similarly treated children without the biliary changes (68).

Treatment options for adults with the AIH-PSC overlap syndrome are limited (41) (Table 3). Mycophenolate mofetil has been ineffective in children with AIH and sclerosing cholangitis (69) and adults with classical PSC (70), and the reported experiences with the calcineurin inhibitors (cyclosporine and tacrolimus) in the treatment of the AIH-PSC overlap syndrome have been sparse $(5,27,71)$. Conventional corticosteroid regimens have been effective in $20 \%$ to $100 \%$ of patients $(2,18,20,27,38)$, and corticosteroids in combination with low-dose ursodeoxycholic acid have had similarly inconsistent results $(27,72)$. Despite these limitations, combined therapy with corticosteroids and low-dose ursodeoxycholic acid has been endorsed by the EASL and the American Association for the Study of Liver Diseases with the recognition that this recommendation is not strongly evidence based $(5,30,31)$.

Prednisone or prednisolone $(0.5 \mathrm{mg} / \mathrm{kg} /$ day tapered to $10 \mathrm{mg} /$ day to $15 \mathrm{mg} /$ day) and azathioprine ( $50 \mathrm{mg} /$ day to $75 \mathrm{mg} /$ day) in combination with ursodeoxycholic acid $(15 \mathrm{mg} / \mathrm{kg} / \mathrm{day}$ to $20 \mathrm{mg} / \mathrm{kg} / \mathrm{day})$ has been associated with a better survival in adults with the AIH-PSC overlap syndrome than that in adults with classical PSC (72), and a similar dosing schedule may be considered in adults with this overlap syndrome (Table 3). High-dose ursodeoxycholic acid $(28 \mathrm{mg} / \mathrm{kg} /$ day to $30 \mathrm{mg} / \mathrm{kg} /$ day) should not be used because individuals with classical PSC who have been treated in this fashion have experienced increased frequencies of death from hepatic failure, need for liver transplantation and serious complications of advanced liver disease (73). High serum concentrations of the toxic metabolite lithocholic acid may have contributed to these dire consequences (74).

Treatment and outcome of the AIH-cholestatic overlap syndrome Patients with the AIH-cholestatic overlap syndrome respond less well to conventional corticosteroid therapy than patients with classical $\mathrm{AIH}$, and they respond as poorly as patients with AIH and large-duct PSC (2). Improvement to normal or near-normal laboratory tests and liver tissue was not achieved in six patients during conventional corticosteroid therapy, and the frequencies of disease progression and liver transplantation were $17 \%$ and $33 \%$, respectively (2). A similarly poor response to conventional corticosteroid therapy has been reported in patients classified as having AIH and small-duct PSC, and they responded more poorly to corticosteroid therapy than patients with large-duct PSC (27).

Treatment options for patients with the AIH-cholestatic overlap syndrome are also limited (Table 3). Corticosteroid regimens have been generally ineffective, and therapies with low-dose ursodeoxycholic acid alone or in combination with corticosteroids have had variable results $(2,11,27)$. No treatment has been preferred or endorsed by a liver society. Therapy usually involves corticosteroids alone or in combination with low-dose ursodeoxycholic acid ( $13 \mathrm{mg} / \mathrm{kg} /$ day to $15 \mathrm{mg} / \mathrm{kg} / \mathrm{day}$ ) depending on the predominant manifestations $(4,6)$.

\section{SUMMARY}

The overlap syndromes of AIH are clinical descriptions that have clinical relevance because they respond variably to conventional corticosteroid therapy $(2,5,6,11)$. The key diagnostic and prognostic features of these syndromes reflect the presence of cholestasis in an otherwise classical syndrome of AIH (4), and they may be evident as an atypical elevation of the serum alkaline phosphatase or GGT level, histological features of bile duct injury or loss, or abnormal cholangiogram indicating a sclerosing injury of the intrahepatic and/or extrahepatic biliary tree. These disconcerting cholestatic findings in $\mathrm{AIH}$ may be supplemented by the presence of AMA (2).

The atypical findings can then be clustered into syndromes that resemble other classical diagnoses such as $\mathrm{PBC}$ or PSC, and their concurrence with classical AIH can justify the designations of the overlap syndromes of AIH-PBC and AIH-PSC $(2,5,6)$. The cholestatic laboratory and histological findings that cannot be ascribed to classical $\mathrm{PBC}$ or PSC but which coexist with AIH can then be designated as an AIH-cholestatic overlap syndrome, recognizing that this designation probably includes patients with small duct PSC and AMA-negative $\operatorname{PBC}(6,27,43)$.

The overlap syndromes lack treatments that have emerged from large randomized clinical trials, and the therapies that have been endorsed by the liver societies and liver interest groups are based on small, single-centre experiences with diseases that have not been diagnosed by uniform criteria or treated with standardized regimens. The important clinical directive is to treat the predominant component of each syndrome with its appropriate therapy (4). Because AIH is the predominant disease in the overlap syndromes of the present review, conventional corticosteroid therapy is the cornerstone of management.

Corticosteroid therapy alone using a lower dose in combination with azathioprine is appropriate for adults with the AIH-PBC overlap syndrome who have a serum alkaline phosphatase level $<2$-fold ULN $(2,6)$ (Table 3). A corticosteroid-based regimen is also appropriate for children with AIH and sclerosing cholangitis (41). Ursodeoxycholic acid ( $13 \mathrm{mg} / \mathrm{kg} /$ day to $15 \mathrm{mg} / \mathrm{kg} / \mathrm{day}$ ) is appropriate as adjunctive therapy in patients with the AIH-PBC overlap syndrome who have a serum alkaline phosphatase level $>2$-fold $\operatorname{ULN}(5,9,19,30)$ or $\mathrm{AIH}$ PSC overlap syndrome $(5,30,31)$. Patients with the AIH-cholestatic overlap syndrome are candidates for corticosteroids alone or in combination with low-dose ursodeoxycholic acid depending on the degree of cholestasis $(4,6,11)$.

\section{CONCLUDING VIEWPOINTS}

The overlap syndromes are not valid pathological entities, but their recognition is important because they can influence management strategies $(6,23)$. They should be sought in all patients with AIH who are refractory to conventional corticosteroid therapy, have cholestatic features, or concurrent inflammatory bowel disease. They cannot be assimilated into conventional diagnostic categories and should maintain separate classifications that emphasize their predominant component $(5,6)$. Current designations that imply the simultaneous occurrence of two diseases in the same individual are presumptuous, and they should be modified to emphasize the predominant component of the syndrome and the modifying cholestatic feature that denotes the atypicality and influences the treatment strategy $(5,6)$. Terms such as 'AIH with destructive cholangitis' or 'AIH with biliary sclerosis' may be more accurate and clinically valuable than terms such as 'AIH-PBC' or 'AIH-PSC overlap syndrome'. The international liver societies and liver interest groups must standardize diagnostic criteria and designations that accurately reflect the clinical relevance and nature of these syndromes as currently understood.

DISCLOSURES: Presented, in part, during the Canadian Digestive Diseases Week and annual winter meeting of the Canadian Association for the Study of the Liver, Victoria, British Columbia, March 3, 2013. This review did not receive financial support from a funding agency or institution, and Albert J Czaja has no conflict of interests to declare. 


\section{REFERENCES}

1. Czaja AJ. The variant forms of autoimmune hepatitis. Ann Intern Med 1996;125:588-98.

2. Czaja AJ. Frequency and nature of the variant syndromes of autoimmune liver disease. Hepatology 1998;28:360-5.

3. Czaja AJ. Variant forms of autoimmune hepatitis. Curr Gastroenterol Rep 1999;1:63-70.

4. Ben-Ari Z, Czaja AJ. Autoimmune hepatitis and its variant syndromes. Gut 2001;49:589-94.

5. Boberg KM, Chapman RW, Hirschfield GM, et al. Overlap syndromes: The International Autoimmune Hepatitis Group (IAIHG) position statement on a controversial issue. J Hepatol 2011;54:374-85.

6. Czaja AJ. The overlap syndromes of autoimmune hepatitis. Dig Dis Sci 2013;58:326-43.

7. Alvarez F, Berg PA, Bianchi FB, et al. International Autoimmune Hepatitis Group Report: Review of criteria for diagnosis of autoimmune hepatitis. J Hepatol 1999;31:929-38.

8. Kenny RP, Czaja AJ, Ludwig J, Dickson ER. Frequency and significance of antimitochondrial antibodies in severe chronic active hepatitis. Dig Dis Sci 1986;31:705-11.

9. Heurgue A, Vitry F, Diebold MD, et al. Overlap syndrome of primary biliary cirrhosis and autoimmune hepatitis: A retrospective study of 115 cases of autoimmune liver disease. Gastroenterol Clin Biol 2007;31:17-25.

10. Ludwig J, Czaja AJ, Dickson ER, LaRusso NF, Wiesner RH. Manifestations of nonsuppurative cholangitis in chronic hepatobiliary diseases: Morphologic spectrum, clinical correlations and terminology. Liver 1984;4:105-16.

11. Czaja AJ, Carpenter HA, Santrach PJ, Moore SB. Autoimmune cholangitis within the spectrum of autoimmune liver disease. Hepatology 2000;31:1231-8.

12. Czaja AJ, Carpenter HA. Autoimmune hepatitis with incidental histologic features of bile duct injury. Hepatology 2001;34:659-65.

13. Czaja AJ, Muratori P, Muratori L, Carpenter HA, Bianchi FB. Diagnostic and therapeutic implications of bile duct injury in autoimmune hepatitis. Liver Int 2004;24:322-9.

14. Czaja AJ. Autoimmune hepatitis. Part B: diagnosis. Expert Rev Gastroenterol Hepatol 2007;1:129-43.

15. Johnson PJ, McFarlane IG. Meeting report: International Autoimmune Hepatitis Group. Hepatology 1993;18:998-1005.

16. Czaja AJ, Carpenter HA. Validation of scoring system for diagnosis of autoimmune hepatitis. Dig Dis Sci 1996;41:305-14.

17. Boberg KM, Fausa O, Haaland T, et al. Features of autoimmune hepatitis in primary sclerosing cholangitis: An evaluation of 114 primary sclerosing cholangitis patients according to a scoring system for the diagnosis of autoimmune hepatitis. Hepatology 1996;23:1369-76.

18. McNair AN, Moloney M, Portmann BC, Williams R, McFarlane IG. Autoimmune hepatitis overlapping with primary sclerosing cholangitis in five cases. Am J Gastroenterol 1998;93:777-84.

19. Chazouilleres O, Wendum D, Serfaty L, et al. Primary biliary cirrhosis-autoimmune hepatitis overlap syndrome: Clinical features and response to therapy. Hepatology 1998;28:296-301.

20. Al-Chalabi T, Portmann BC, Bernal W, McFarlane IG, Heneghan MA. Autoimmune hepatitis overlap syndromes: An evaluation of treatment response, long-term outcome and survival. Aliment Pharmacol Ther 2008;28:209-20.

21. Lohse AW, zum Buschenfelde KH, Franz B, et al. Characterization of the overlap syndrome of primary biliary cirrhosis (PBC) and autoimmune hepatitis: Evidence for it being a hepatitic form of PBC in genetically susceptible individuals. Hepatology 1999;29:1078-84.

22. Luth S, Kanzler S, Frenzel C, et al. Characteristics and long-term prognosis of the autoimmune hepatitis/primary sclerosing cholangitis overlap syndrome. J Clin Gastroenterol 2009;43:75-80.

23. Durazzo M, Premoli A, Paschetta E, et al. Overlap syndromes of autoimmune hepatitis: An open question. Dig Dis Sci 2013;58:344-8.

24. Efe C, Wahlin S, Ozaslan E, et al. Autoimmune hepatitis/primary biliary cirrhosis overlap syndrome and associated extrahepatic autoimmune diseases. Eur J Gastroenterol Hepatol 2012;24:531-4.

25. Angulo P, Maor-Kendler Y, Lindor KD. Small-duct primary sclerosing cholangitis: a long-term follow-up study. Hepatology 2002;35:1494-500.

26. Muratori P, Muratori L, Gershwin ME, et al. 'True' antimitochondrial antibody-negative primary biliary cirrhosis, low sensitivity of the routine assays, or both? Clin Exp Immunol 2004;135:154-8.

27. Olsson R, Glaumann H, Almer S, et al. High prevalence of small duct primary sclerosing cholangitis among patients with overlapping autoimmune hepatitis and primary sclerosing cholangitis. Eur J Intern Med 2009;20:190-6.

28. Silveira MG, Talwalkar JA, Angulo P, Lindor KD. Overlap of autoimmune hepatitis and primary biliary cirrhosis: Long-term outcomes. Am J Gastroenterol 2007;102:1244-50.

29. Neuhauser M, Bjornsson E, Treeprasertsuk S, et al. Autoimmune hepatitis-PBC overlap syndrome: A simplified scoring system may assist in the diagnosis. Am J Gastroenterol 2010;105:345-53.

30. Beuers U, Boberg KM, Chapman RW, et al. EASL clinical practice guidelines: Management of cholestatic liver diseases. J Hepatol 2009;51:237-67.

31. Chapman R, Fevery J, Kalloo A, et al. Diagnosis and management of primary sclerosing cholangitis. Hepatology 2010;51:660-78.

32. Hennes EM, Zeniya M, Czaja AJ, et al. Simplified criteria for the diagnosis of autoimmune hepatitis. Hepatology 2008;48:169-76.

33. Czaja AJ. Comparability of probable and definite autoimmune hepatitis by international diagnostic scoring criteria. Gastroenterology 2011;140:1472-80.

34. Carpenter HA, Czaja AJ. The role of histologic evaluation in the diagnosis and management of autoimmune hepatitis and its variants. Clin Liver Dis 2002;6:685-705.

35. Chazouilleres O, Wendum D, Serfaty L, Rosmorduc O, Poupon R. Long term outcome and response to therapy of primary biliary cirrhosis-autoimmune hepatitis overlap syndrome. J Hepatol 2006;44:400-6.

36. Dienes HP, Erberich H, Dries V, Schirmacher P, Lohse A. Autoimmune hepatitis and overlap syndromes. Clin Liver Dis 2002;6:349-62, vi.

37. Kuiper EM, Zondervan PE, van Buuren HR. Paris criteria are effective in diagnosis of primary biliary cirrhosis and autoimmune hepatitis overlap syndrome. Clin Gastroenterol Hepatol 2010;8:530-4.

38. Perdigoto R, Carpenter HA, Czaja AJ. Frequency and significance of chronic ulcerative colitis in severe corticosteroid-treated autoimmune hepatitis. J Hepatol 1992;14:325-31.

39. Abdalian R, Dhar P, Jhaveri K, et al. Prevalence of sclerosing cholangitis in adults with autoimmune hepatitis: Evaluating the role of routine magnetic resonance imaging. Hepatology 2008;47:949-57.

40. Lewin M, Vilgrain V, Ozenne V, et al. Prevalence of sclerosing cholangitis in adults with autoimmune hepatitis: A prospective magnetic resonance imaging and histological study. Hepatology 2009;50:528-37.

41. Gregorio GV, Portmann B, Karani J, et al. Autoimmune hepatitis/ sclerosing cholangitis overlap syndrome in childhood: A 16-year prospective study. Hepatology 2001;33:544-53.

42. Mieli-Vergani G, Vergani D. Unique features of primary sclerosing cholangitis in children. Curr Opin Gastroenterol 2010;26:265-8.

43. Kim WR, Ludwig J, Lindor KD. Variant forms of cholestatic diseases involving small bile ducts in adults. Am J Gastroenterol 2000;95:1130-8.

44. Ben-Ari Z, Dhillon AP, Sherlock S. Autoimmune cholangiopathy: Part of the spectrum of autoimmune chronic active hepatitis. Hepatology 1993;18:10-5.

45. Goodman ZD, McNally PR, Davis DR, Ishak KG. Autoimmune cholangitis: A variant of primary biliary cirrhosis. Clinicopathologic and serologic correlations in 200 cases. Dig Dis Sci 1995;40:1232-42.

46. Michieletti P, Wanless IR, Katz A, et al. Antimitochondrial antibody negative primary biliary cirrhosis: A distinct syndrome of autoimmune cholangitis. Gut 1994;35:260-5.

47. Omagari K, Ikuno N, Matsuo I, et al. Autoimmune cholangitis syndrome with a bias towards primary biliary cirrhosis. Pathology 1996;28:255-8.

48. Sherlock S. Ludwig Symposium on biliary disorders. Autoimmune cholangitis: A unique entity? Mayo Clin Proc 1998;73:184-90.

49. Poupon R. Autoimmune overlapping syndromes. Clin Liver Dis 2003;7:865-78.

50. Czaja AJ. Overlap syndrome of primary biliary cirrhosis and autoimmune hepatitis: A foray across diagnostic boundaries. J Hepatol 2006;44:251-2. 
51. Yeoman AD, Westbrook RH, Al-Chalabi T, et al. Diagnostic value and utility of the simplified International Autoimmune Hepatitis Group (IAIHG) criteria in acute and chronic liver disease. Hepatology 2009;50:538-45.

52. Manns MP, Czaja AJ, Gorham JD, et al. Practice guidelines of the American Association for the Study of Liver Diseases. Diagnosis and management of autoimmune hepatitis. Hepatology 2010;51:2193-213.

53. Lindgren S, Glaumann H, Almer S, et al. Transitions between variant forms of primary biliary cirrhosis during long-term follow-up. Eur J Intern Med 2009;20:398-402.

54. Abdo AA, Bain VG, Kichian K, Lee SS. Evolution of autoimmune hepatitis to primary sclerosing cholangitis: A sequential syndrome. Hepatology 2002;36:1393-9.

55. Poupon R, Chazouilleres O, Corpechot C, Chretien Y. Development of autoimmune hepatitis in patients with typical primary biliary cirrhosis. Hepatology 2006;44:85-90.

56. Gossard AA, Lindor KD. Development of autoimmune hepatitis in primary biliary cirrhosis. Liver Int 2007;27:1086-90.

57. Czaja AJ. Performance parameters of the conventional serological markers for autoimmune hepatitis. Dig Dis Sci 2011;56:545-54.

58. Montano-Loza AJ, Carpenter HA, Czaja AJ. Frequency, behavior, and prognostic implications of antimitochondrial antibodies in type 1 autoimmune hepatitis. J Clin Gastroenterol 2008;42:1047-53.

59. Czaja AJ, Santrach PJ, Breanndan Moore S. Shared genetic risk factors in autoimmune liver disease. Dig Dis Sci 2001;46:140-7.

60. Burak KW, Urbanski SJ, Swain MG. A case of coexisting primary biliary cirrhosis and primary sclerosing cholangitis: A new overlap of autoimmune liver diseases. Dig Dis Sci 2001;46:2043-7.

61. Kingham JG, Abbasi A. Co-existence of primary biliary cirrhosis and primary sclerosing cholangitis: A rare overlap syndrome put in perspective. Eur J Gastroenterol Hepatol 2005;17:1077-80.

62. Jeevagan A. Overlap of primary biliary cirrhosis and primary sclerosing cholangitis - a rare coincidence or a new syndrome. Int J Gen Med 2010;3:143-6.

63. Czaja AJ. Genetic factors affecting the occurrence, clinical phenotype, and outcome of autoimmune hepatitis. Clin Gastroenterol Hepatol 2008;6:379-88.
64. Czaja AJ, Carpenter HA. Sensitivity, specificity, and predictability of biopsy interpretations in chronic hepatitis. Gastroenterology 1993;105:1824-32.

65. Czaja AJ. Autoimmune hepatitis. Part A: Pathogenesis. Expert Rev Gastroenterol Hepatol 2007;1:113-28.

66. Bhanji RA, Mason AL, Girgis S, Montano-Loza AJ. Liver transplantation for overlap syndromes of autoimmune liver diseases. Liver Int 2013;33:210-9.

67. Joshi S, Cauch-Dudek K, Wanless IR, et al. Primary biliary cirrhosis with additional features of autoimmune hepatitis: Response to therapy with ursodeoxycholic acid. Hepatology 2002;35:409-13.

68. Mieli-Vergani G, Vergani D. Autoimmune liver diseases in children - what is different from adulthood? Best Pract Res Clin Gastroenterol 2011;25:783-95.

69. Aw MM, Dhawan A, Samyn M, Bargiota A, Mieli-Vergani G. Mycophenolate mofetil as rescue treatment for autoimmune liver disease in children: A 5-year follow-up. J Hepatol 2009;51:156-60.

70. Talwalkar JA, Angulo P, Keach JC, et al. Mycophenolate mofetil for the treatment of primary sclerosing cholangitis. Am J Gastroenterol 2005; $100: 308-12$

71. Lawrence SP, Sherman KE, Lawson JM, Goodman ZD. A 39 year old man with chronic hepatitis. Semin Liver Dis 1994;14:97-105.

72. Floreani A, Rizzotto ER, Ferrara F, et al. Clinical course and outcome of autoimmune hepatitis/primary sclerosing cholangitis overlap syndrome. Am J Gastroenterol 2005;100:1516-22.

73. Lindor KD, Kowdley KV, Luketic VA, et al. High-dose ursodeoxycholic acid for the treatment of primary sclerosing cholangitis. Hepatology 2009;50:808-14.

74. Sinakos E, Marschall HU, Kowdley KV, et al. Bile acid changes after high-dose ursodeoxycholic acid treatment in primary sclerosing cholangitis: Relation to disease progression. Hepatology 2010;52:197-203.

75. Doherty DG, Penzotti JE, Koelle DM, et al. Structural basis of specificity and degeneracy of $\mathrm{T}$ cell recognition: Pluriallelic restriction of $\mathrm{T}$ cell responses to a peptide antigen involves both specific and promiscuous interactions between the $\mathrm{T}$ cell receptor, peptide, and HLA-DR. J Immunol 1998;161:3527-35. 


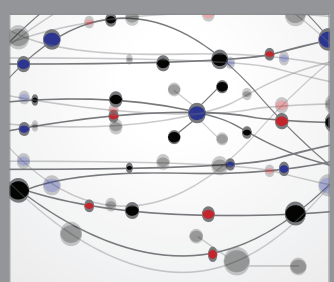

The Scientific World Journal
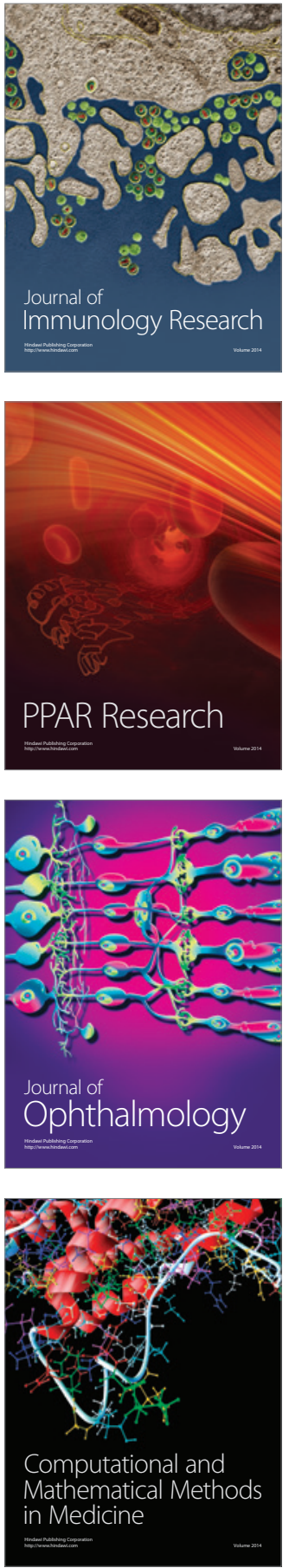

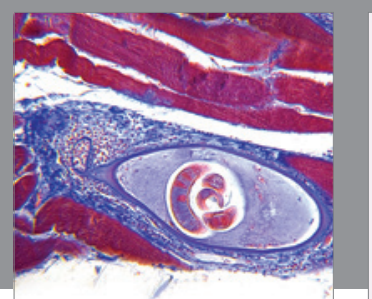

Gastroenterology Research and Practice

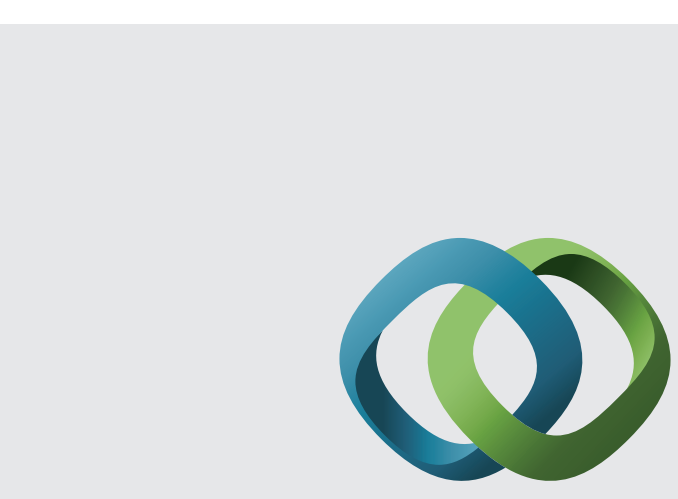

\section{Hindawi}

Submit your manuscripts at

http://www.hindawi.com
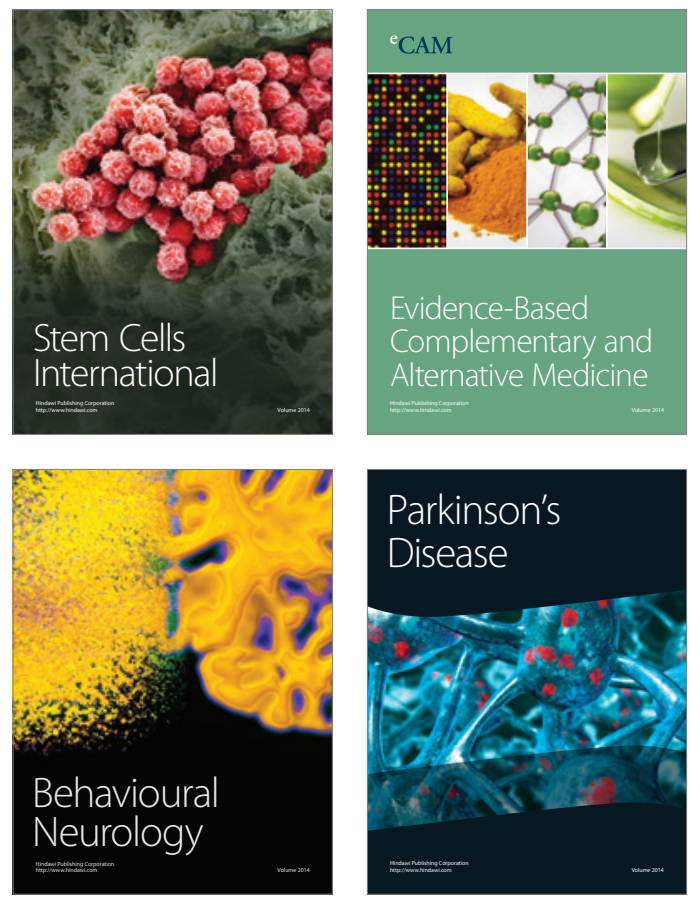
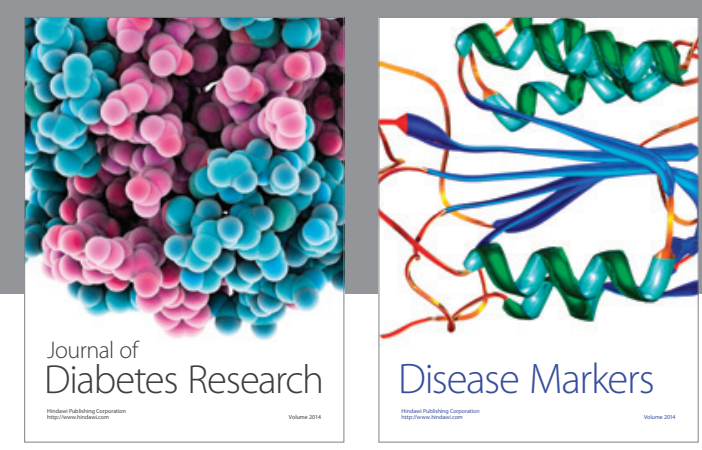

Disease Markers
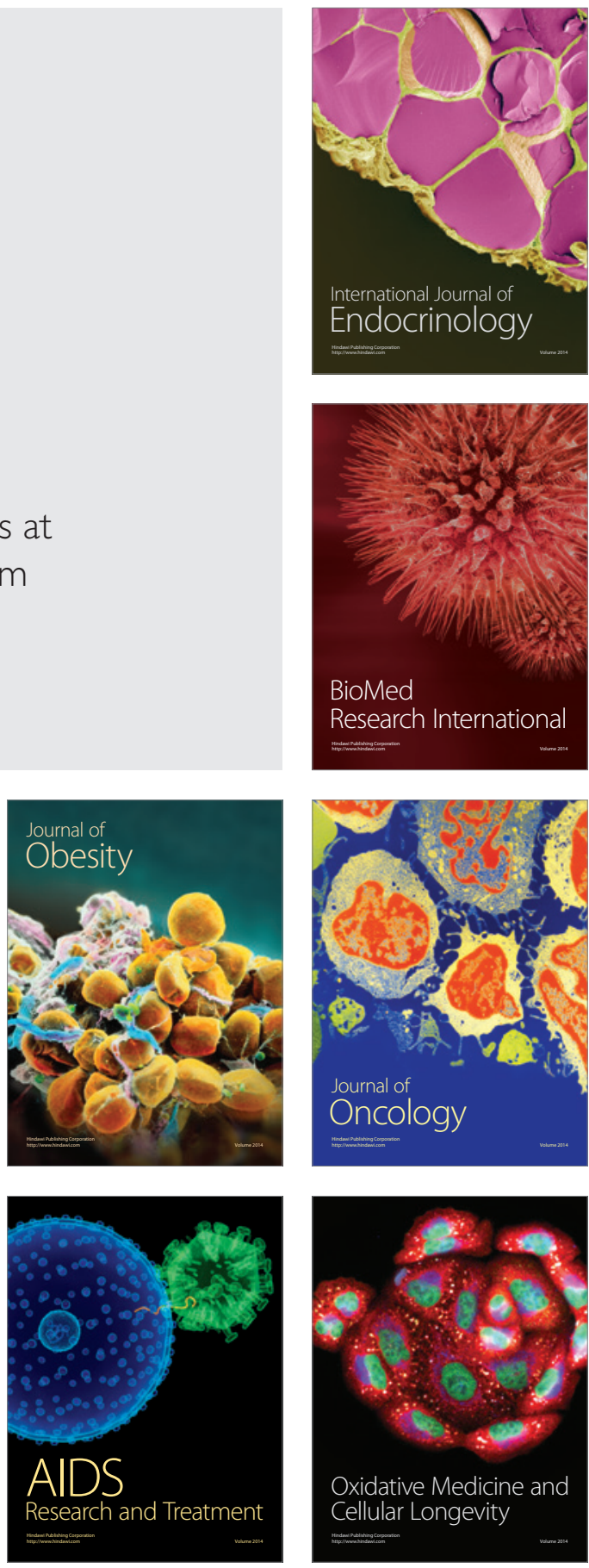